\title{
Ammonium Uptake and Assimilation are Required for Rice Defense against Sheath Blight Disease
}

\author{
W.J. CHI ${ }^{1,2,3 *}$, Z.Y. WANG ${ }^{2 * *}$, J.M. LIU ${ }^{4}$, C. ZHANG ${ }^{2 *}$, Y.H. WU ${ }^{2 *}$ and Y.J. BAI ${ }^{1 *}$ \\ ${ }^{1}$ Institute of Plant Protection, Liaoning Academy of Agricultural Sciences, Shenyang, 110161 China \\ ${ }^{2}$ College of Plant Protection, Shenyang Agricultural University, Shenyang, 110866 China \\ ${ }^{3}$ College of Life Engineering, Shenyang Institute of Technology, Fushun, 113122 China \\ ${ }^{4}$ Department of Agricultural and Biological Technology, WenZhou Agricultural Science Research Institute \\ (WenZhou Vocational College of Science \&Technology), Wenzhou, 325006 China
}

(Received 12 April 2018; 4 July 2018;

Communicated by J. Zhang)

\begin{abstract}
Nitrogen $(\mathrm{N})$ is an important nutrient for plant growth and yield production, and rice grown in paddy soil mainly uses ammonium $\left(\mathrm{NH}_{4}^{+}\right)$as its $\mathrm{N}$ source. Previous studies have shown that $\mathrm{N}$ status is tightly connected to plant defense; however, the roles of $\mathrm{NH}_{4}^{+}$uptake and assimilation in rice sheath blight disease response have not been studied previously. Here, we analyzed the effects of different $\mathrm{N}$ sources on plant defense against Rhizoctonia solani. The results indicated that rice plants grown in $\mathrm{N}$-free conditions had higher resistance to sheath blight than those grown under $\mathrm{N}$ conditions. In greater detail, rice plants cultured with glutamine as the sole $\mathrm{N}$ source were more susceptible to sheath blight disease compared to the groups using $\mathrm{NH}_{4}^{+}$and nitrate $\left(\mathrm{NO}_{3}^{-}\right)$as sole $\mathrm{N}$ sources. $\mathrm{N}$ deficiency severely inhibited plant growth; therefore, ammonium transporter 1;2 overexpressors (AMT1;2 OXs) were generated to test their growth and defense ability under low $\mathrm{N}$ conditions. AMT1;2 OXS increased $\mathrm{N}$ use efficiency and exhibited less susceptible symptoms to $R$. solani and highly induced the expression of $P B Z 1$ compared to the wild-type controls upon infection of $R$. solani. Furthermore, the glutamine synthetase $1 ; 1(G S 1 ; 1)$ mutant $(g s 1 ; 1)$ was more susceptible to $R$. solani infection than the wild-type control, and the genetic combination of $A M T 1 ; 2 O X$ and $g s 1 ; 1$ revealed that $A M T 1 ; 2 O X$ was less susceptible to $R$. solani and required $G S 1 ; 1$ activity. In addition, cellular $\mathrm{NH}_{4}^{+}$content was higher in $A M T 1 ; 2 O X$ and gs 1; 1 plants, indicating that $\mathrm{NH}_{4}^{+}$was not directly controlling plant defense. In conclusion, the present study showed that the activation of $\mathrm{NH}_{4}^{+}$uptake and assimilation were required for rice resistance against sheath blight disease.
\end{abstract}

Keywords: AMT, assimilation, sheath blight, defense, GS1;1, rice

Abbreviations: AMT: ammonium transporter; Os: Oryza sativa; GS: glutamine synthetase; N: nitrogen; $R$. solani: Rhizoctonia solani; OX: overexpression; ORF: open reading frame; PBZ1: Probenazole-inducible gene

\footnotetext{
*Corresponding authors; E-mails: zhangchong0816@163.com,wuyh7799@163.com; cycbyj@126.com

***These authors contributed equally to this work
} 


\section{Introduction}

In most soils, nitrate $\left(\mathrm{NO}_{3}^{-}\right)$and ammonium $\left(\mathrm{NH}_{4}^{+}\right)$represent the major forms of nitrogen (N) uptake in higher plants. The $\mathrm{NO}_{3}^{-}$and $\mathrm{NH}_{4}^{+}$ions accumulate in cells by direct uptake from the rhizosphere via $\mathrm{NO}_{3}^{-}$transporters and $\mathrm{NH}_{4}^{+}$transporters, with $\mathrm{NO}_{3}^{-}$further metabolized to $\mathrm{NH}_{4}^{+}$. The $\mathrm{NH}_{4}^{+}$is then assimilated into glutamate via the glutamine synthetase (GS)/glutamate synthase cycle. Glutamine and asparagine have been identified as the major forms of organic $\mathrm{N}$ in the xylem and are translocated from the roots to the shoots (Fukumorita and Chino 1982). $\mathrm{N}$ is important for plant growth and yield production, and which is counted as $2 \%$ of plant dry weight.

$\mathrm{N}$ status is also closely associated with plant defense mechanisms. In Arabidopsis, ammonium transporter $1 ; 2$ overexpressors $(A M T 1 ; 1)$ alter basal defense, generating resistance against Pseudomonas syringe and Plectosphaerella cucumerina (Pastor et al. 2014), and the expressions of $\mathrm{NH}_{4}^{+}$transporters and $\mathrm{NO}_{3}^{-}$transporters have been found to be altered by both biotic and abiotic stresses (Fagard et al. 2014). In sorghum, the expressions of $S b A M T 3 ; 1$ and $S b A M T 4$ were greatly induced locally in roots colonized by arbuscular mycorrhizal fungi (Koegel et al. 2013). Ammonium supply was reported to protect tomatoes against $P$ s. syringae by an increase in cellular reactive oxygen species levels (Fernandez-Crespo et al. 2015). In addition, amino acids play a role in the defense response of plants. In Arabidopsis, inoculation with avirulent Ps. syringae pv. tomato (Pto) expressing avrRpt2 activates transcription of genes involved in amino acid biosynthesis (Scheideler et al. 2002). Metabolic profiling has also shown that inoculation with virulent or avirulent pathogens alters amino acid contents in Arabidopsis (Ward et al. 2010). The lhtl mutant with reduced levels of proline, glutamine, and alanine shows strong resistance against various types of pathogens including bacteria, filamentous fungi, and oomycetes (Liu et al. 2010). In rice, treatment of the roots with glutamate induces systemic resistance to rice blast disease, partially via salicylic acid signaling (Kadotani et al. 2016). In addition, glutamate treatment has been found to induce defense response genes in rice (Kan et al. 2017). These findings suggest that cellular $\mathrm{N}$ levels or $\mathrm{N}$ signals are closely associated with plant defense.

Sheath blight is one of the three major diseases in rice and is caused by the fungal pathogen $R$. solani (Savary 1995). Sheath blight threatens rice throughout the growth cycle from seedling to heading and causes lesions on leaves, sheaths, and panicles. During the late stage of infection, the whole plant withers and lodges (Savary et al. 1995). Sheath blight can reduce rice yield by $8-50 \%$, depending on disease severity, crop stage at which the infection occurs, and environmental conditions (Savary 2000). However, the effect of $\mathrm{N}$ levels on sheath blight disease has not been reported previously. Here, we analyzed the function of different $\mathrm{N}$ sources on sheath blight disease. In addition, the growth patterns of $A M T 1 ; 2$ overexpressing plants were examined under a relatively low $\mathrm{N}$ content as well as the response to sheath blight disease. Further genetic analysis was performed using the $G S 1 ; 1$ mutant $(g s 1 ; 1)$ and genetic combination between $g s 1 ; 1$ and $A M T 1 ; 2 O X$ to test the function of $\mathrm{N}$ uptake and assimilation in sheath blight defense in rice. The data presented here provided new insight into the role of $\mathrm{N}$ status on plant growth and pathogen resistance in rice plants. 


\section{Materials and Methods}

Mutant isolation and plant growth

The gs 1;1 mutant (PFG_3A-09512) was obtained from a rice T-DNA database (http:// signal.salk.edu/cgi-bin/RiceGE/) (An et al. 2003). The mutant lines and transgenic plants were derived from the Japonica rice cultivar 'Dongjin.' To analyze $\mathrm{N}$ effects on plant growth and defense, rice plants were cultured in N-free Murashige and Skoog (MS) medium (Duchefa) containing $10 \mathrm{mM} \mathrm{NH}_{4} \mathrm{NO}_{3}$ (high $\mathrm{N}, \mathrm{HN}$ ) or $0.1 \mathrm{mM} \mathrm{NH}_{4} \mathrm{NO}_{3}$ (low $\mathrm{N}$, LN) for 5 days.

\section{Plants expressing vector construction and transformation}

To generate $A M T 1 ; 2$ overexpressing plants, $A M T 1 ; 2$ ORF sequences were amplified by polymerase chain reaction (PCR) and further cloned into HindIII and BamHI sites of the PGA1611 binary vector (Dou et al. 2016). The primers used to amplify $A M T 1 ; 2$ ORF are listed in Table S1*. PGA1611-AMT1;2 was transformed into rice calli via the Agrobacterium-mediated transformation method (Hiei et al. 1994). The LBA4404 Agrobacterium strain was used in the experiments.

\section{Determination of $\mathrm{NH}_{4}^{+}$contents}

Enzymatic determination of $\mathrm{NH}_{4}^{+}$contents in roots and shoots of 5-day-old seedlings grown in $0.5 \mathrm{X}$ MS medium for 5 days was performed using an F-kit (Roche) according to the manufacturer's instructions (Oliveira et al. 2002).

\section{$R N A$ extraction and real-time reverse transcription PCR (qRT-PCR)}

Total cellular RNA was isolated from 30 plant tissues with TRIzol (Takara, Dalian, Liaoning, China) and $1 \mu \mathrm{g}$ of total RNA was subsequently treated with RQ-RNase free DNase (Promega, Madison, WI, USA) to eliminate genomic DNA contamination. For cDNA synthesis, a GoScript Reverse Transcription Kit was used following the manufacturer's instructions (Promega, Madison, WI, USA). Subsequently, qRT-PCR was performed in triplicate using the SYBR Green Mix (Bio-Rad). PCR products were quantified using the Illumina Research Quantity software Illumina Eco 3.0 (Illumina, San Diego, California, USA) and the values were normalized against Ubiquitin levels from the same samples to analyze the ratio for each gene. The primers used for the qRT-PCR are listed in Table S1.

\section{Plant inoculation}

All plants were grown under greenhouse conditions (temperature, $23-30{ }^{\circ} \mathrm{C}$, humidity

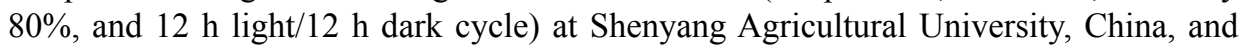
propagated by selfing. One-month-old plants were used for inoculation with $R$. solani

\footnotetext{
*Further details about the Electronic Supplementary Material (ESM) can be found at the end of the article.
} 
AG1-1A. In brief, a $10 \mathrm{~cm}$ long piece was cut from the second youngest leaf of the main tiller and placed on a moistened filter paper in a Petri dish (diameter, $36 \mathrm{~cm}$; height, $2.5 \mathrm{~cm}$ ). At least 10 leaves from each line were used as one replicate, with four replications per line in a completely randomized design. Colonized potato dextrose agar blocks (diameter, $7 \mathrm{~mm}$ ) were excised using a circular cutter and placed on the abaxial surface of each leaf piece. The leaves were incubated in a chamber with continuous light at $25^{\circ} \mathrm{C}$ for $72 \mathrm{~h}$. The filter paper was kept moist with sterile water. After $72 \mathrm{~h}$, the lesion length of each leaf piece was measured and presented as percentage of area covered with lesions in a leaf (Prasad and Eizenga 2008).

\section{Northern blot analysis}

Formaldehyde gels (1.3\%) were prepared in MOPS ((3-(N-morpholino) propanesulfonic acid)/ethylenediaminetetraacetic acid [EDTA]) buffer (0.5 M MOPS, pH 7.0; $0.01 \mathrm{M}$ $\mathrm{Na}_{2}$ EDTA, $\mathrm{pH}$ 7.5) for Northern blot analysis. Twenty micrograms of RNA for each sample were heat-denatured in a formaldehyde/formamide solution. The gels were electrophoresed and further washed with 10X SSC for $1 \mathrm{~h}$ before being blotted onto a Hybond $\mathrm{N}+$ membrane (Amersham Pharmacia Biotech, U.K.). Ethidium Bromide (EtBr) staining for rRNA was used as the loading control. The membrane and a 32P-labeled gene-specific probe were hybridized at $65^{\circ} \mathrm{C}$ in Church buffer (1\% BSA, $200 \mu \mathrm{M}$ EDTA, $0.5 \mathrm{M}$ sodium phosphate, $7 \%$ SDS). The membranes were autoradiographed using Fuji X-ray film. The $A M T 1 ; 2$ ORF fragment was used as the probe.

\section{Statistical analysis}

Statistical analysis was performed using Prism 5 (GraphPad, San Diego, CA, USA). All data were expressed as means \pm standard error. One-way analysis of variance was performed, followed by Bonferroni's multiple comparison test, and the differences were considered significant at $P<0.05$ (Brady et al. 2015).

\section{Results \\ $N$ nutrition enhanced susceptibility of rice to sheath blight disease}

To analyze the relationship between $\mathrm{N}$ status and sheath blight disease, rice seedlings were grown in water for 2 weeks before being transferred to different $\mathrm{N}$ sources ( $\mathrm{N}$-free, $\mathrm{NO}_{3}^{-}, \mathrm{NH}_{4}^{+}$, and glutamine) containing media culture for another week. Then, the 3-weekold plants were inoculated with $R$. solani AG1-1A strain (Fig. 1A). After 4 days of inoculation, symptoms were analyzed in each treatment group. The results indicated that plants grown in $\mathrm{N}$-free conditions had significantly higher resistance to $R$. solani AG1-1A than plants cultured with $\mathrm{N}$ sources (Figure $1 \mathrm{~B}, \mathrm{C}$ ). In addition, plants cultured with glutamine as the sole $\mathrm{N}$ source were more susceptible to sheath blight disease, whereas those cultured with $\mathrm{NO}_{3}^{-}$were less susceptible and the $\mathrm{NH}_{4}^{+}$supplemented group exhibited moder- 


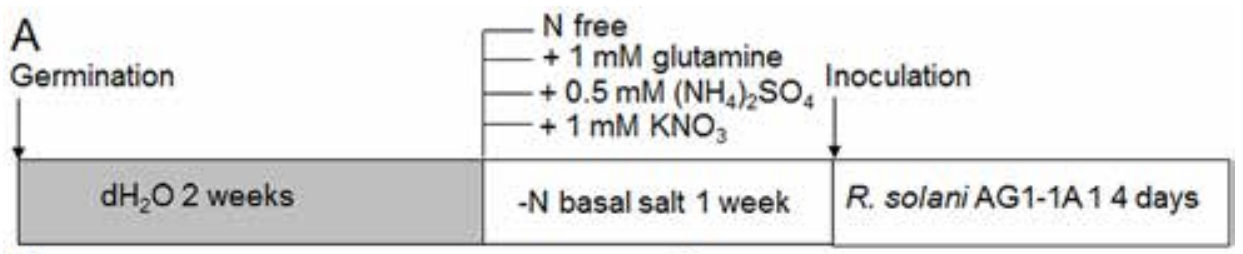

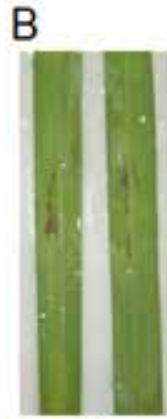

$-\mathrm{N}$

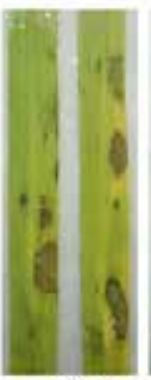

$\mathrm{NO}_{3}{ }^{-}$

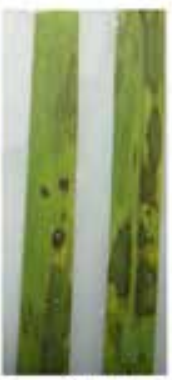

$\mathrm{NH}_{4}{ }^{+}$

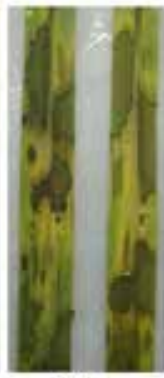

Gin
C

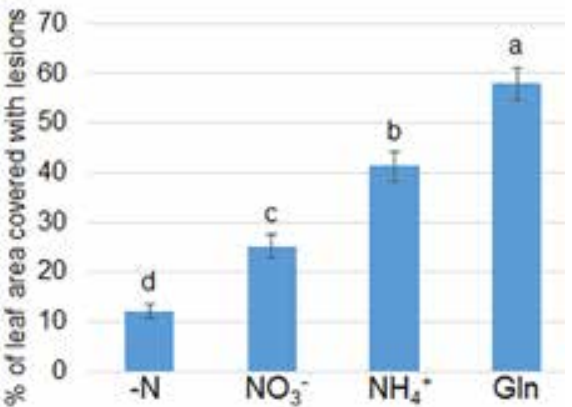

Figure 2. The effects of $\mathrm{N}$ concentrations on rice seedling growth. (A) Wild-type plants were grown in the modified MS medium containing $10 \mathrm{mM} \mathrm{NH}_{4} \mathrm{NO}_{3}$ (high nitrogen, $\mathrm{HN}$ ) or $0.1 \mathrm{mM} \mathrm{NH}_{4} \mathrm{NO}_{3}$ (low nitrogen, $\mathrm{LN}$ ) for 5 days. Scale bar $=1 \mathrm{~cm}$. (B) The seminal shoot and root lengths of plant shown in (A) were calculated $(n>10)$. Different letters indicate significant differences at $\mathrm{P}<0.05$
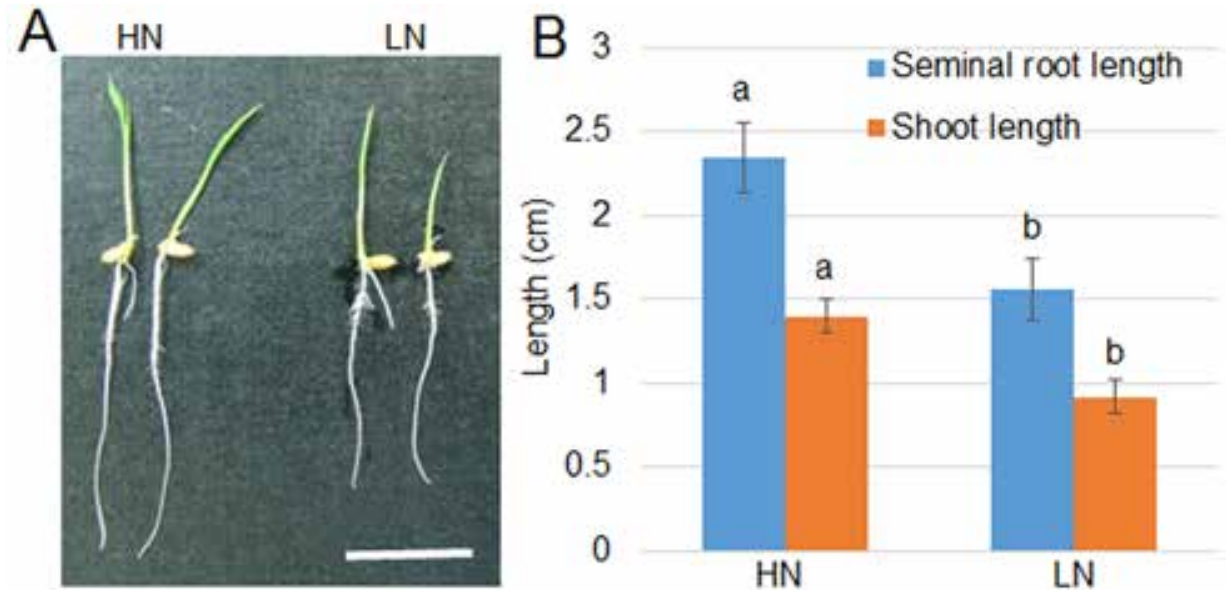

Figure 2. The effects of $\mathrm{N}$ concentrations on rice seedling growth. (A) Wild-type plants were grown in the modified MS medium containing $10 \mathrm{mM} \mathrm{NH}_{4} \mathrm{NO}_{3}$ (high nitrogen, $\mathrm{HN}$ ) or $0.1 \mathrm{mM} \mathrm{NH}_{4} \mathrm{NO}_{3}$ (low nitrogen, $\mathrm{LN}$ ) for 5 days. Scale bar $=1 \mathrm{~cm}$. (B) The seminal shoot and root lengths of plant shown in (A) were calculated $(n>10)$. Different letters indicate significant differences at $\mathrm{P}<0.05$ 
ate susceptibility (Fig. 1B, C). These results indicate that different $\mathrm{N}$ sources have different effects on rice defense against sheath blight disease.

As plants cultured in $\mathrm{N}$-free medium significantly promoted rice resistance to sheath blight disease, plant growth was monitored in $\mathrm{LN}$ and $\mathrm{HN}$ culture media. Rice seedlings were grown in $\mathrm{HN}$ or LN for 5 days, and the root and shoot lengths were measured. The data showed that seedling size was obviously larger under $\mathrm{HN}$ culture conditions than LN culture conditions (Fig. 2B). These results showed that lower $\mathrm{N}$ in the growth medium might had enhanced rice resistance to sheath blight, yet plant growth was affected.

\section{Overexpression of AMT1;2 increased $N$ use efficiency and resistance} to sheath blight disease

To test whether modification of $\mathrm{NH}_{4}^{+}$uptake ability was also a plant defense response, $A M T 1 ; 2$ overexpression lines were generated. Over 10 individual lines were generated, and 4 lines $(A M T 1 ; 2 O X 1-4)$ had their expression levels further analyzed using Northern blot analysis. $A M T 1 ; 2$ was weakly expressed in wild-type plants, yet it was highly ex-
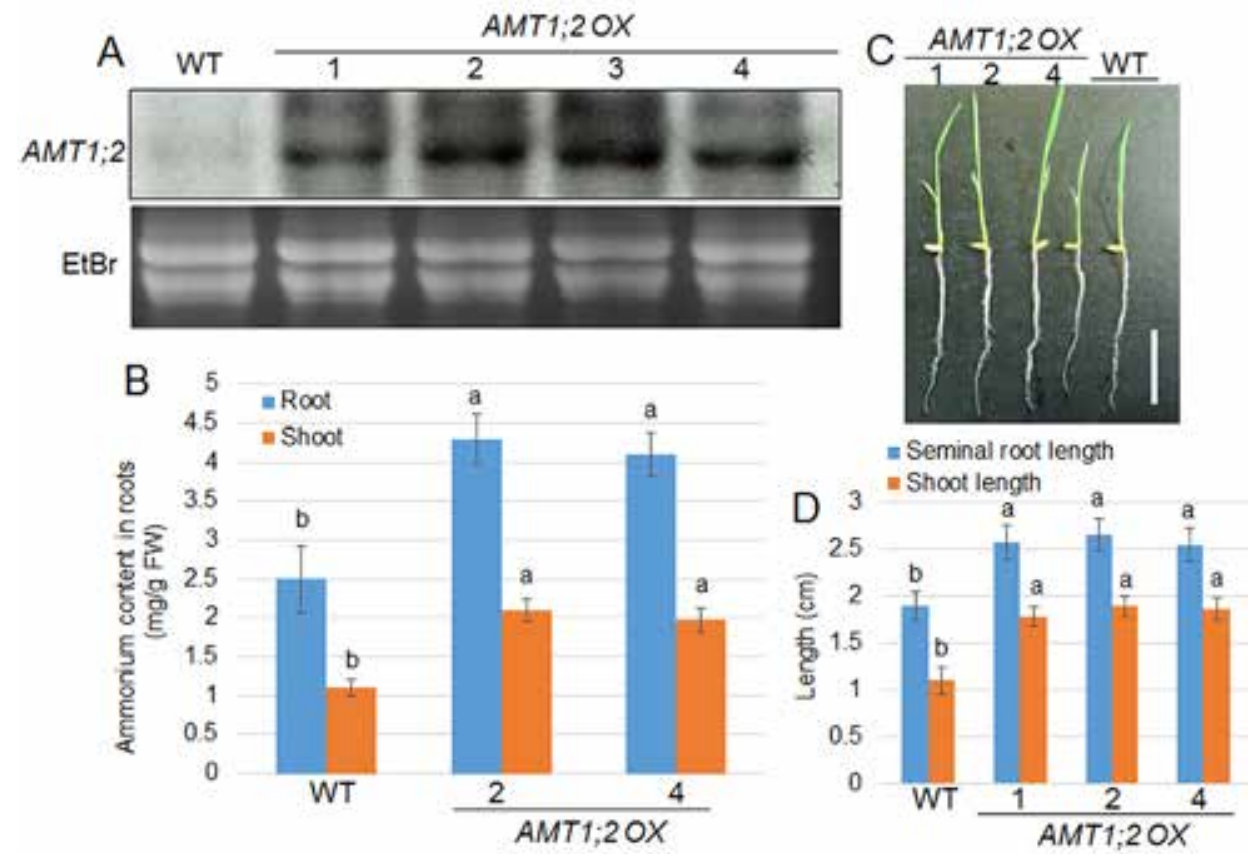

Figure 3. Cellular $\mathrm{NH}_{4}^{+}$contents and $\mathrm{N}$-dependent growth of $A M T 1 ; 2$ overexpressors. (A) The expression levels of $A M T 1 ; 2$ was detected by Northern blot analysis using RNAs extracted from 1-week-old wild-type and $A M T 1 ; 2$ overexpressors (AMT1;2 OX1, 2,3,4) seedlings. (B) Cellular $\mathrm{NH}_{4}{ }^{+}$contents in shoots and roots of wild-type and two independent $A M T 1 ; 2 O X$ lines (2 and 4) were measured. (C) Wild-type and three independent $A M T 1 ; 2 O X$ lines $\left(1,2\right.$, and 4) grown in the modified MS solution containing $0.1 \mathrm{mM} \mathrm{NH}_{4} \mathrm{NO}_{3}$ for 5 days. Scale bar $=1 \mathrm{~cm}$. (D) The shoot and root lengths of plants shown in $(\mathrm{C})$ were calculated. Different letters indicate significant differences at $\mathrm{P}<0.05$ 
pressed in $A M T 1 ; 2 O X$ lines. The expression levels were higher in $O X 2$ and $O X 3$ than in $O X 1$ and $O X 4$ (Fig. 3A). Next, cellular $\mathrm{NH}_{4}^{+}$contents were measured in the shoots and roots of wild-type and two $A M T 1 ; 2 O X$ lines $(O X 2$ and $O X 4)$. Roots contained higher $\mathrm{NH}_{4}^{+}$than the shoots, and cellular $\mathrm{NH}_{4}^{+}$contents were much higher in AMT1;2 OXs than in wild-type plants (Fig. 3B). Additionally, the growth of $A M T 1 ; 2 O X S$ under the LN condition was analyzed. The data showed that $A M T 1 ; 2$ OXs developed much longer shoots and roots than wild-type plants (Fig. 3C, D).
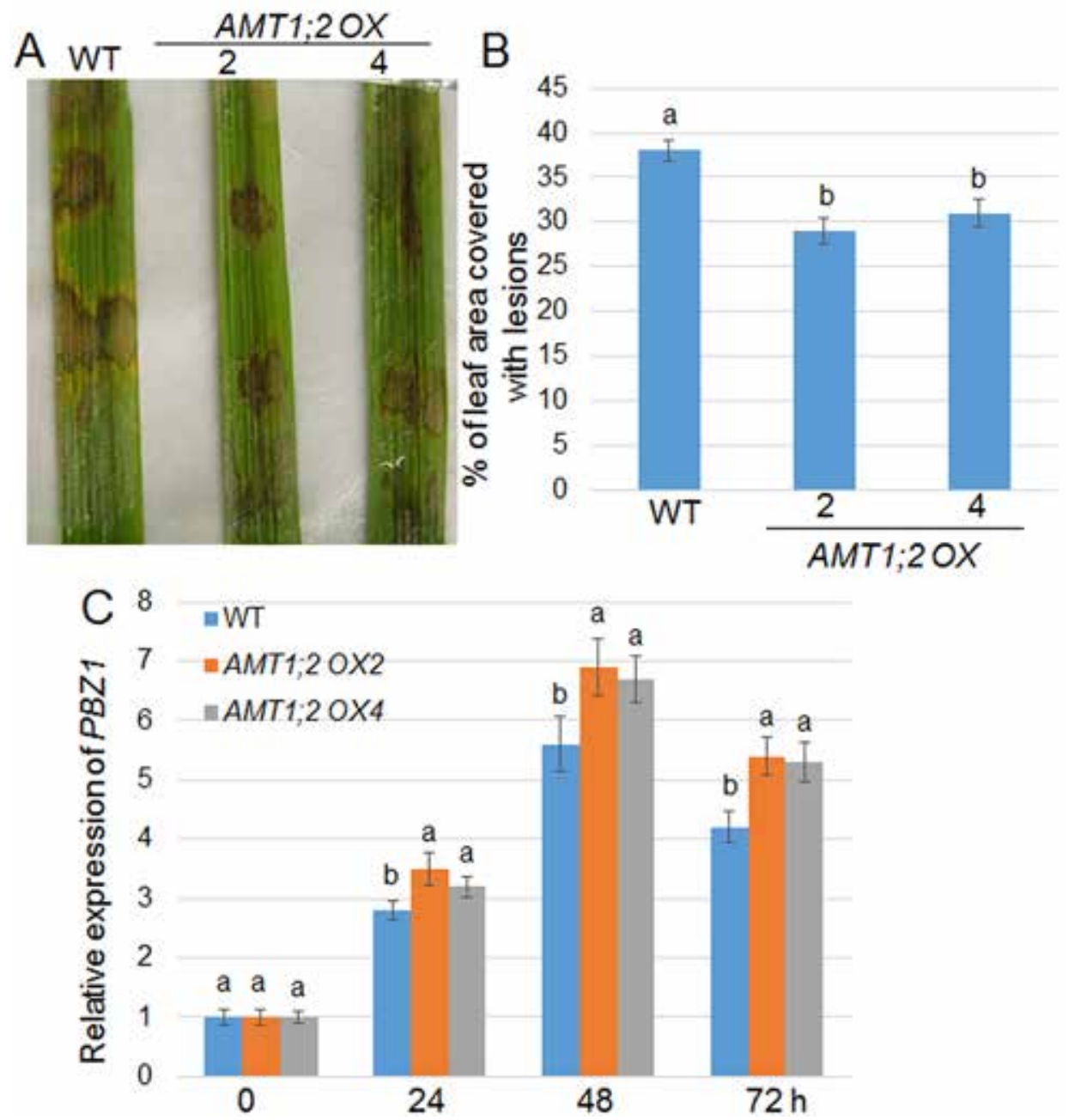

Figure 4. Response of $A M T 1 ; 2 O X$ plants to R. solani. (A) Lesions of 3-week-old wild-type and $A M T 1 ; 2 O X$ plants were photographed after 4 days of $R$. solani AG1-1A inoculation. (B) Percentage of leaf area covered with lesions shown in (A) were calculated $(\mathrm{n}>15)$. (C) The 3-week-old plants were inoculated with $R$. solani AG1-1A. PBZ1 expressions after 0, 24, 48, and $72 \mathrm{~h}$ of $R$. solani inoculation were examined in wild-type and two $A M T 1 ; 2 O X$ lines. Different letters indicate significant differences at $\mathrm{P}<0.05$ 
Further, the response of $A M T 1 ; 2 O X$ to $R$. solani AG1-1A was examined. The 1-monthold plant leaves were inoculated with $R$. solani and the lesion area on the leaves were calculated. The results indicated that wild-type and $A M T 1 ; 2 O X S$ were susceptible to sheath blight disease, with the lesion area in the leaves of $A M T 1 ; 2 O X s$ much lower than in the wild-type plants (Fig. 4A, B). The marker gene expression test showed that $P B Z 1$ expression was induced upon $R$. solani inoculation, and the induction folds were significantly higher in $A M T 1 ; 2 O X S$ than in wild-type plants.

\section{GS1;1 mutant is more susceptible to R. solani}

As $A M T 1 ; 2 O X \mathrm{~s}$ were less susceptible to $R$. solani than wild-type plants, the role of the $\mathrm{NH}_{4}^{+}$assimilation process in sheath blight disease defense was further examined. GS was the first step enzyme to catalyze the $\mathrm{NH}_{4}{ }^{+}$assimilate into the amide group of glutamine. The gs 1;1 mutant with T-DNA inserted in the second exon was shown in Figure 5A. To
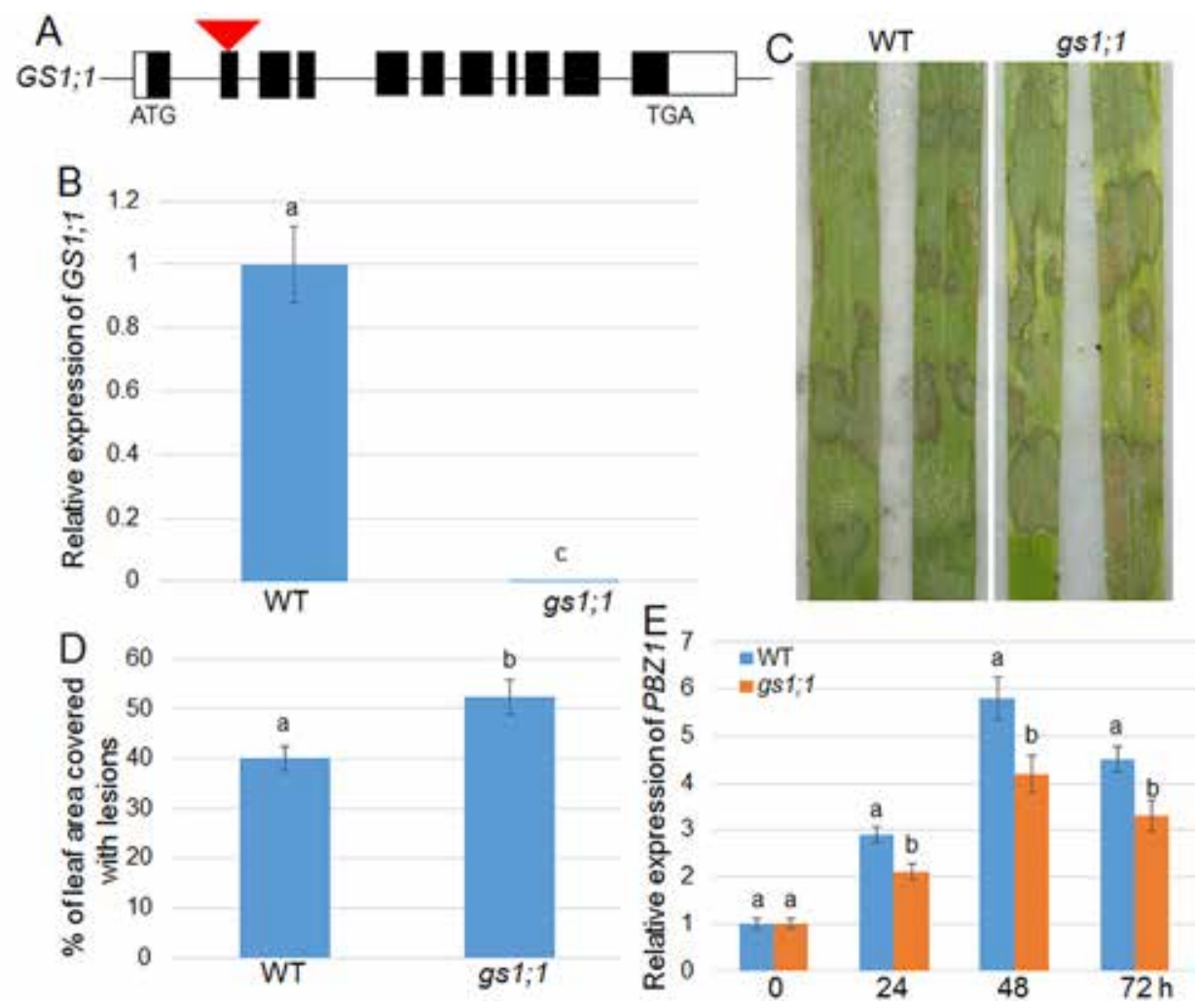

Figure 5. Response of GS1;1 mutant to R. solani. (A) The diagram showed the genomic structure of the GS1;1 T-DNA insertional mutant $\left(g_{S} 1 ; 1\right)$. Black and white boxes indicate the exons and UTR regions, respectively. The triangle in the second exon indicates T-DNA insertion sites. (B) GS1;1 expression levels in wild-type and gs 1;1 mutant were analyzed using qRT-PCR. (C) Lesions of 3-week-old wild-type and gs 1;1 mutant were photographed after 4 days of $R$. solani AG1-1A inoculation. (D) Percentage of leaf area covered with lesions shown in (C) were calculated $(\mathrm{n}>15)$. (E) R. solani infection-mediated $P B Z 1$ expression patterns in wild-type and $g s 1 ; 1$ mutant were analyzed after $0,24,48$, and $72 \mathrm{~h}$ of inoculation. Different letters indicate significant 

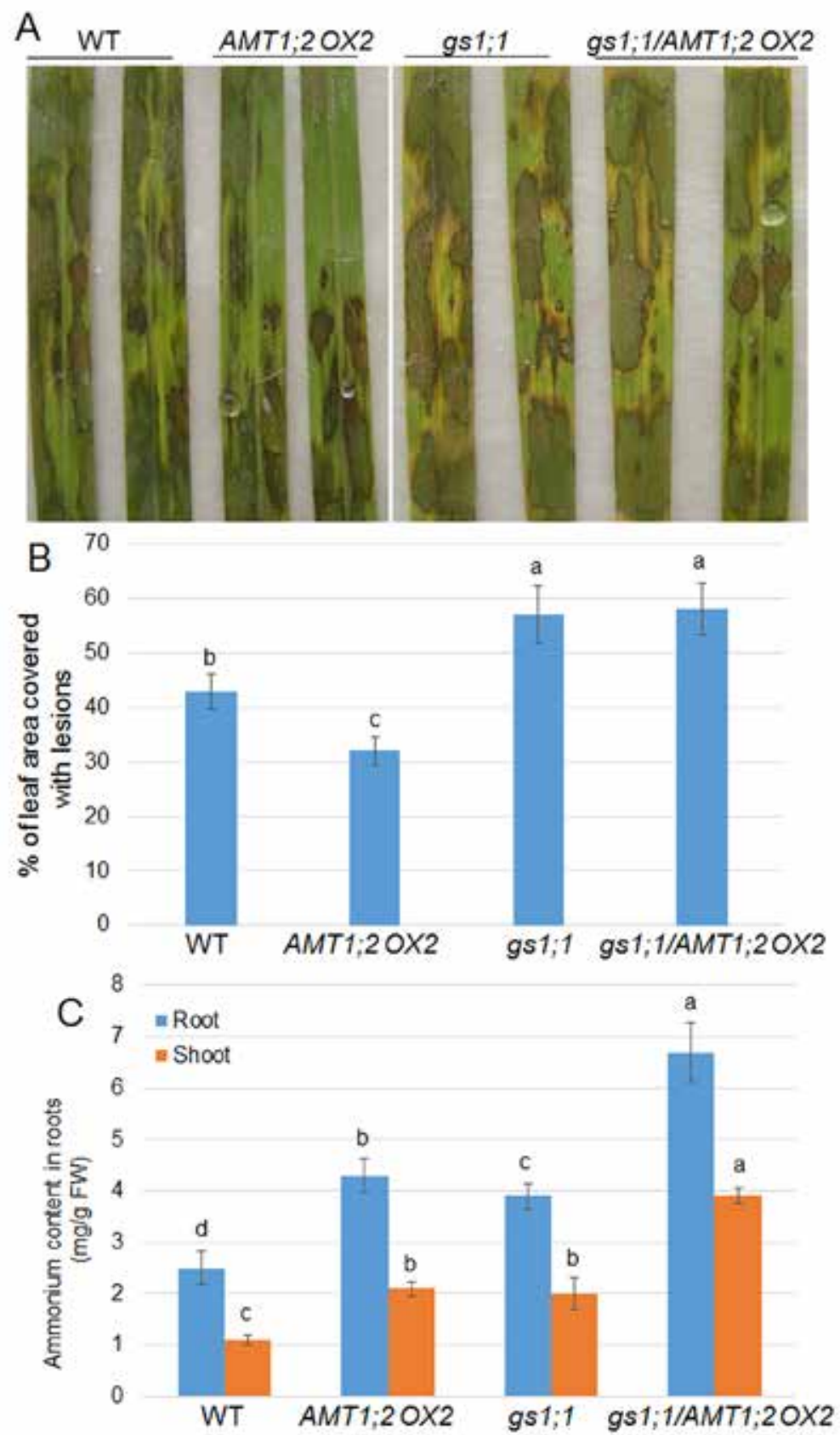

Figure 6. Effect of $G S 1 ; 1$ mutation on $A M T 1 ; 2 O X$ plant defense against $R$. solani. (A) Lesions of 3-week-old wild-type, $A M T 1 ; 2 O X 2$, gs 1;1, and $g s 1 ; 1 / A M T 1 ; 2 O X 2$ mutants were photographed after 4 days of $R$. solani AG1-1A inoculation. (B) Percentage of leaf area covered with lesions shown in (A) were calculated $(\mathrm{n}>15)$. (C) Cellular $\mathrm{NH}_{4}{ }^{+}$contents in shoots and roots of wild-type, AMT1;2 OX2, gs 1; 1 , and gs 1;1/AMT1;2 OX2 were measured. Different letters indicate significant differences at $\mathrm{P}<0.05$ 
verify whether it was a knock-out mutant, qRT-PCR analysis was performed, and the results showed that no visible transcript was detected in the gs $1 ; 1$ mutant (Fig. 5B). The response of $g_{s} 1 ; 1$ to $R$. solani AG1-1A was evaluated. The 1-month-old wild-type and gs 1;1 mutant leaves were inoculated with $R$. solani, and the lesion area on the leaves calculated. The results showed that $g s 1 ; 1$ was more susceptible to $R$. solani than the wildtype control (Fig. 5C, D). The PBZ1 expression patterns were further examined after $R$. solani inoculation. The qRT-PCR data showed that $P B Z 1$ levels were similar in the wild-type and $g_{s} 1 ; 1$ before $R$. solani inoculation, and $P B Z 1$ was less induced in $g s 1 ; 1$ than in the wild-type after inoculation (Fig. 5E).

\section{AMT1;2 OX plants are relatively resistant to $\mathrm{R}$. solani and require gs 1;1 activity}

$A M T 1 ; 2 O X$ plants exhibited less susceptible symptoms to $R$. solani infection than $g_{s} 1 ; 1$ plants that were more susceptible than the wild-type controls. Therefore, we examined whether the $A M T 1 ; 2 O X$ influence on $R$. solani defense depends on the $\mathrm{NH}_{4}^{+}$assimilation process or not. To investigate this hypothesis, the genetic combination between $A M T 1 ; 2$ $O X 2$ and $g s 1 ; 1$ was generated and $R$. solani response was evaluated. The results indicated that segregated $A M T 1 ; 2 O X 2$ was less susceptible to sheath blight disease, whereas $g s 1 ; 1$ and $g s 1 ; 1 / A M T 1 ; 2 O X 2$ plants were more susceptible than wild-type plants to sheath blight disease (Fig. 6A, B). To specify whether $\mathrm{NH}_{4}^{+}$contents controlled the defense against $R$. solani, in the present study the cellular $\mathrm{NH}_{4}^{+}$contents were measured in the shoots and roots of wild-type, $g s 1 ; 1, g s 1 ; 1 / A M T 1 ; 2 O X 2$, and $A M T 1 ; 2 O X$ seedlings. The gs 1;1 and $A M T 1 ; 2 O X 2$ shoots and roots accumulated higher $\mathrm{NH}_{4}^{+}$than the wild-type shoots and roots, and cellular $\mathrm{NH}_{4}^{+}$contents were higher in AMT1;2 OX2 than in $g s 1 ; 1$. In addition, gs 1;1/AMT1;2 $O X 2$ plants accumulated much higher $\mathrm{NH}_{4}^{+}$than $A M T 1 ; 2$ $O X 2$ and $g s 1 ; 1$ plants (Fig. 6C).

\section{Discussion}

$\mathrm{N}$ is important for plant growth and yield production as well as for plant response to pathogens (Fagard et al. 2014). In most soils, $\mathrm{NO}_{3}^{-}$and $\mathrm{NH}_{4}^{+}$represent the major forms for $\mathrm{N}$ uptake in higher plants. The reduction of $\mathrm{NO}_{3}^{-}$to $\mathrm{NH}_{4}^{+}$consumes $12-26 \%$ of photosynthetically-generated reductants. Therefore, the use of $\mathrm{NH}_{4}^{+}$as a $\mathrm{N}$ source conserves a large amount of energy for plants (Bloom 1997; Noctor and Foyer 1998; Patterson et al. 2010). Because of the higher abundance of $\mathrm{NH}_{4}^{+}$in paddy soils, $\mathrm{NH}_{4}^{+}$nutrition is of particular importance for the production of rice plants. In the present study, we cultured rice plants with $\mathrm{NO}_{3}^{-}, \mathrm{NH}_{4}^{+}$, and glutamine as the sole $\mathrm{N}$ source or under $\mathrm{N}$-free conditions. Further, R. solani AG1-1A was inoculated to examine the role of different $\mathrm{N}$ nutrition on sheath blight disease. The data indicated that $\mathrm{N}$ starvation significantly increased resistance to sheath blight disease, whereas glutamine feeding severe the disease index. $\mathrm{NO}_{3}^{-}$ treatment had a weak effect whereas $\mathrm{NH}_{4}^{+}$nutrition exhibited a moderate effect on sheath blight disease (Fig. 1), suggesting that different $\mathrm{N}$ sources had different effects on defense responses. We speculate that different $\mathrm{N}$ sources might act as signal molecules to modu- 
late their signals or that $\mathrm{N}$ assimilation is important for rice defense. Previous reports have indicated that glutamate treatment in rice plants increased resistance to blast disease (Kadotani et al. 2016); however, our results indicated that amino acids played different roles in sheath blight disease defense.

$\mathrm{N}$ starvation to plants obviously enhanced rice resistance to sheath blight disease; however, it significantly affected plant growth with shorter shoot and root lengths (Fig. 2). $A M T 1 ; 1$ overexpression increased $\mathrm{N}$ use efficiency, developed bigger plants, and increased rice yield under limited $\mathrm{NH}_{4}^{+}$in growth medium (Ranathunge et al. 2014). $A M T 1 ; 2$ overexpressing plants developed longer roots and shoots under LN condition (Fig. 3). In addition, $A M T 1 ; 2$ overexpression promoted rice resistance to sheath blight disease, suggesting that activation of $\mathrm{NH}_{4}^{+}$uptake activated plant immunity. Marker gene $P B Z 1$ expression was similar in wild-type and $A M T 1 ; 2 O X$ seedlings; however, the induction folds were higher in $A M T 1 ; 2 O X$ than in wild-type plants, indicating that $A M T 1 ; 2$ overexpression activated defense-related genes in a pathogen dependent manner. $A M T 1 ; 2$ overexpression increased cellular $\mathrm{NH}_{4}^{+}$contents. The $G S 1 ; 1$ mutant $(g s 1 ; 1)$ has been reported previously to accumulate less amino acids and severely affect rice yield production (Tabuchi et al. 2005). To specify whether the activation of the defense system depended on cellular accumulation of $\mathrm{NH}_{4}^{+}$or assimilation products, the response of GS1;1mutant $\left(g_{s} 1 ; 1\right)$ to sheath blight disease was examined. The $g s 1 ; 1$ mutant was more susceptible to $R$. solani infection than the wild-type control; however, the $G S 1 ; 1$ mutation accumulated more cellular $\mathrm{NH}_{4}^{+}$, suggesting that cellular $\mathrm{NH}_{4}^{+}$contents were not associated with sheath blight disease.

$A M T 1 ; 2 O X$ plants exhibited less susceptible symptoms to sheath blight disease, whereas the $g s 1 ; 1$ mutant was more susceptible to sheath blight disease. To determine whether $A M T 1 ; 2 O X$ phenotype was associated with the $\mathrm{NH}_{4}^{+}$assimilation process, $A M T 1 ; 2 O X$ and gs 1;1 mutants were crossed and the double mutant response to $R$. solani was examined. The results indicated that $A M T 1 ; 2 O X$ phenotype against $R$. solani disappeared when $G S 1 ; 1$ was mutated, and cellular $\mathrm{NH}_{4}^{+}$contents were much higher than in $A M T 1 ; 2 O X$ and $g s 1 ; 1$. This result strongly suggested that $A M T 1 ; 2 O X$ might be less susceptible to sheath blight disease because of the accumulation of more metabolites rather than increased cellular $\mathrm{NH}_{4}^{+}$contents. Exogenous feeding of $\mathrm{N}$ nutrition accelerated rice sheath blight disease. In tomato, exogenously treated with $\mathrm{NH}_{4}^{+}$, activated accumulation of reactive oxygen species levels in the cells was found to protect tomatoes against Ps. Syringae (Fernandez-Crespo et al. 2015). However, overexpression of AMT1;2 was less susceptible to sheath blight disease, implying that treatment of higher concentrations of $\mathrm{N}$ might result in an overactivation of its signal or accumulation of metabolites. $A M T 1 ; 2$ overexpression increased $\mathrm{N}$ use efficiency with better development of plants under limited $\mathrm{N}$ conditions, which might more efficiently uptake and utilize $\mathrm{N}$ sources and produce moderate levels of metabolites. Our study identified new evidence that overexpressing $A M T 1 ; 2$, an $\mathrm{NH}_{4}^{+}$transporter gene, increased $\mathrm{N}$ use efficiency as well as resistance against sheath blight disease. These results might be useful to utilize in rice molecular breeding. 


\section{Acknowledgements}

This work was made possible by Natural Science Foundation of Liaoning Province (20170540812), Liaoning industrial post-doc funding, and Shenyang city post-doc funding.

\section{References}

An, S., Park, S., Jeong, D.H., Lee, D.Y., Kang, H.G., Yu, J.H., Hur, J., Kim, S.R., Kim, Y.H., Lee, M., Han, S., Kim, S.J., Yang, J., Kim, E., Wi, S.J., Chung, H.S., Hong, J.P., Choe, V., Lee, H.K., Choi, J.H., Nam, J., Kim, S.R., Park, P.B., Park, K.Y., Kim, W.T., Choe, S., Lee, C.B., An, G. 2003. Generation and analysis of end sequence database for T-DNA tagging lines in rice. Plant Physiol. 133:2040-2047.

Bloom, A.J. 1997. Nitrogen as a limiting factor: Crop acquisition of ammonium and nitrate. Ecology in Agriculture. 145-172.

Brady, S.M., Burow, M., Busch, W., Carlborg, O., Denby, K.J., Glazebrook, J., Hamilton, E.S., Harmer, S.L., Haswell, E.S., Maloof, J.N., Springer, N.M., Kliebenstein, D.J. 2015. Reassess the t test: Interact with all Your Data via ANOVA. Plant Cell 27:2088-2094.

Dou, M., Cheng, S., Zhao, B., Xuan, Y., Shao, M. 2016. The indeterminate domain protein ROC1 regulates chilling tolerance via activation of DREB1B/CBF1 in rice. Int. J. Mol. Sci. 17:233.

Fagard, M., Launay, A., Clement, G., Courtial, J., Dellagi, A., Farjad, M., Krapp, A., Soulie, M.C., MasclauxDaubresse, C. 2014. Nitrogen metabolism meets phytopathology. J. Exp. Bot. 65:5643-5656.

Fernandez-Crespo, E., Scalschi, L., Llorens, E., Garcia-Agustin, P., Camanes, G. 2015. NH ${ }^{4+}$ protects tomato plants against Pseudomonas syringae by activation of systemic acquired acclimation. J. Exp. Bot. 66:67776790.

Fukumorita, T., Chino, M. 1982. Sugar, amino acid and inorganic contents in rice phloem sap. Plant Cell Physiol. 23:273-283.

Hiei, Y., Ohta, S., Komari, T., Kumashiro, T. 1994. Efficient transformation of rice (Oryza sativa L.) mediated by Agrobacterium and sequence analysis of the boundaries of the T-DNA. Plant J. 6:271-282.

Kadotani, N., Akagi, A., Takatsuji, H., Miwa, T., Igarashi, D. 2016. Exogenous proteinogenic amino acids induce systemic resistance in rice. BMC Plant Biol. 16:60.

Kan, C.C., Chung, T.Y., Wu, H.Y., Juo, Y.A., Hsieh, M.H. 2017. Exogenous glutamate rapidly induces the expression of genes involved in metabolism and defense responses in rice roots. BMC Genomics 18:186.

Koegel, S., Ait Lahmidi, N., Arnould, C., Chatagnier, O., Walder, F., Ineichen, K., Boller, T., Wipf, D., Wiemken, A., Courty, P.E. 2013. The family of ammonium transporters (AMT) in Sorghum bicolor: two AMT members are induced locally, but not systemically in roots colonized by arbuscular mycorrhizal fungi. New Phytol. 198:853-865.

Liu, G., Ji, Y., Bhuiyan, N.H., Pilot, G., Selvaraj, G., Zou, J., Wei, Y. 2010. Amino acid homeostasis modulates salicylic acid-associated redox status and defense responses in Arabidopsis. Plant Cell. 22:3845-3863.

Noctor, G., Foyer, C.H. 1998. A re-evaluation of the ATP: NADPH budget during C3 photosynthesis: a contribution from nitrate assimilation and its associated respiratory activity? J. Exp. Bot. 49:1895-1908.

Oliveira, I.C., Brears, T., Knight, T.J., Clark, A., Coruzzi, G.M. 2002. Overexpression of cytosolic glutamine synthetase. Relation to nitrogen, light, and photorespiration. Plant Physiol. 129:1170-1180.

Pastor, V., Gamir, J., Camanes, G., Cerezo, M., Sanchez-Bel, P., Flors, V. 2014. Disruption of the ammonium transporter AMT1.1 alters basal defenses generating resistance against Pseudomonas syringae and Plectosphaerella cucumerina. Front. Plant Sci. 5:231.

Patterson, K., Cakmak, T., Cooper, A., Lager, I., Rasmusson, A.G., Escobar, M.A. 2010. Distinct signalling pathways and transcriptome response signatures differentiate ammonium and nitrate supplied plants. Plant Cell Eviron. 33:1486-1501.

Prasad, B., Eizenga, G.C. 2008. Rice sheath blight disease resistance identified in Oryza spp. Plant Dis. 92:1503-1509. 
Ranathunge, K., El-Kereamy, A., Gidda, S., Bi, Y.M., Rothstein, S.J. 2014. AMT1;1 transgenic rice plants with enhanced $\mathrm{NH}_{4}^{(+)}$permeability show superior growth and higher yield under optimal and suboptimal $\mathrm{NH}_{4}^{\left({ }^{+}\right)}$ conditions. J. Exp. Bot. 65:965-79.

Savary, S., Castilla, N.P., Elazegui, F.A., McLaren, C.G., Ynalvez, M.A., Teng, P.S. 1995. Direct and indirect effects of nitrogen supply and disease source structure on rice sheath blight spread. Phytopathology. 85:959-965.

Savary, S., Willocquet, L., Elazegui, F.A., Castilla, N.P., Teng, P.S. 2000. Rice pest constraints in tropical Asia: quantification of yield losses due to rice pests in a range of production situations. Plant Dis. 84 .

Scheideler, M., Schlaich, N.L., Fellenberg, K., Beissbarth, T., Hauser, N.C., Vingron, M., Slusarenko, A.J., Hoheisel, J.D. 2002. Monitoring the switch from housekeeping to pathogen defense metabolism in Arabidopsis thaliana using cDNA arrays. J. Biol. Chem. 277:10555-10561.

Tabuchi, M., Sugiyama, K., Ishiyama, K., Inoue, E., Sato, T., Takahashi, H., Yamaya, T. 2005. Severe reduction in growth rate and grain filling of rice mutants lacking OsGS1;1, a cytosolic glutamine synthetase 1;1. Plant J. 42:641-651.

Ward, J.L., Forcat, S., Beckmann, M., Bennett, M., Miller, S.J., Baker, J.M., Hawkins, N.D., Vermeer, C.P., Lu, C., Lin, W., Truman, W.M., Beale, M.H., Draper, J., Mansfield, J.W., Grant, M. 2010. The metabolic transition during disease following infection of Arabidopsis thaliana by Pseudomonas syringae pv. tomato. Plant J. 63:443-457.

\section{Electronic Supplementary Material (ESM)}

Electronic Supplementary Material (ESM) associated with this article can be found at the website of CRC at https://akademiai.com/loi/0806

Electronic Supplementary Table S1. Primer sequences 